\title{
Three-dimensional reattached wall jet
}

\author{
Ecoulement tridimensionmel \\ après un élargissement brusque
}

\author{
B.S. Pani* and R.N. Dash**
}

\section{Notations}

The following symbols are used in this paper.

$A=$ Area of cross section of three-dimensional opening

$b \quad=$ Width of three-dimensional opening

$b_{y} \quad=$ Length scale in $x-y$ plane of symmetry

$b_{z}=$ Length scale in $x-z$ plane

$C^{z}=$ Cœfficient in équation 3

$C_{p}=$ Coefficient of mean wall pressure,

$$
\left(p-p_{\infty}\right) /\left(\frac{1}{2} \rho U_{0}^{2}\right)
$$

$C_{p} \quad=$ Coefficient of fluctuating wall pressure,

$$
(\sqrt{\bar{p}, 2}) /\left(\frac{1}{2} \rho U_{0}^{2}\right)
$$

$c_{f}=$ Coefficient of local skin friction,

$$
\left(\tau_{0}\right) /\left(\frac{1}{2} \rho u_{m o}^{2}\right)
$$

\section{Introduction}

Liquid streams issuing from deeply submerged hydraulic outlets can be analysed as turbulent jets. If the opening occupies only a part of the downstream channel width, and the jet issues tangentially to the bed, the flow can be analysed as a three-dimensional wall jet $[5,7,9]$. However, if the confining boundaries are placed at a sufficient distance from the outlet, the jet can be analysed as a three-dimensional free jet, about which extensive information is readily available $[8,13]$.

\footnotetext{
* Assistant Professor in Civil Engineering, IIT Bombay, India. ** Lecturer in Civil Engineering, R.E. College, Rourkela, India.
}

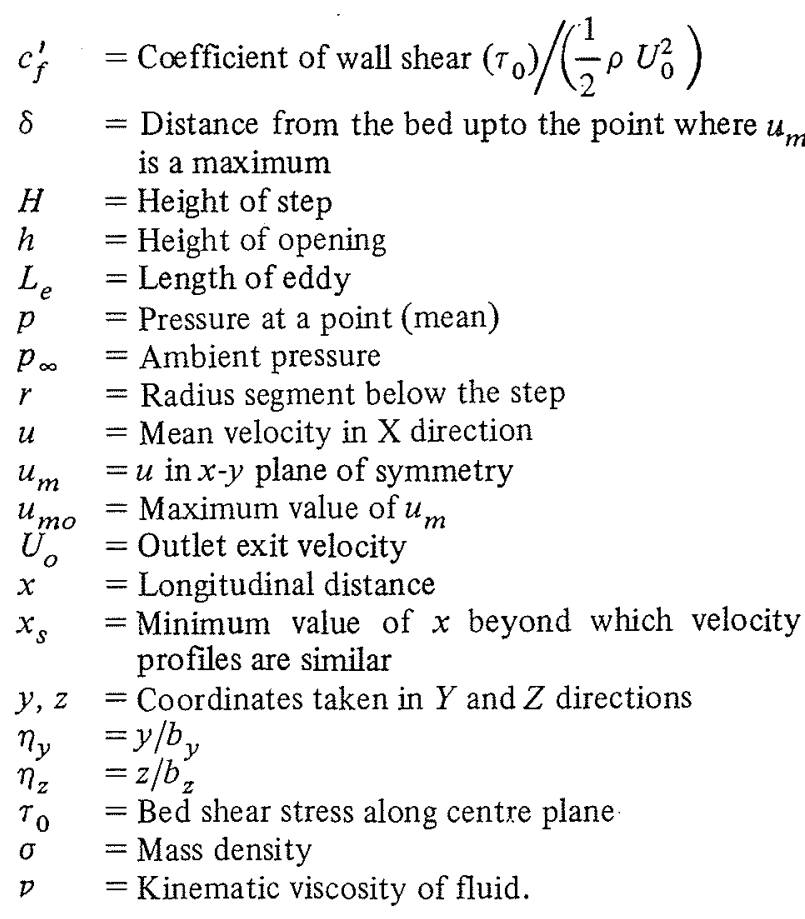

If, on the otherhand, the opening, such as a sluice gate, occupies the full width of the channel, the flow can be analysed as a plane jet [10],

Outlets are sometimes located at small heights above the channel bed and the resulting flow pattern is very complex. For two-dimensional openings, situated over abrupt drops, information regarding the mechanics of flow is available $[1,6]$; but for three-dimensional outlets situated above the bed of the channel no such information seems to exist.

A rectangular or circular free water jet discharging into a wider conveyance channel can produce asymmetry and unsteady flow. The jet can either dive or rise towards the free surface [12] depending on the tail water 


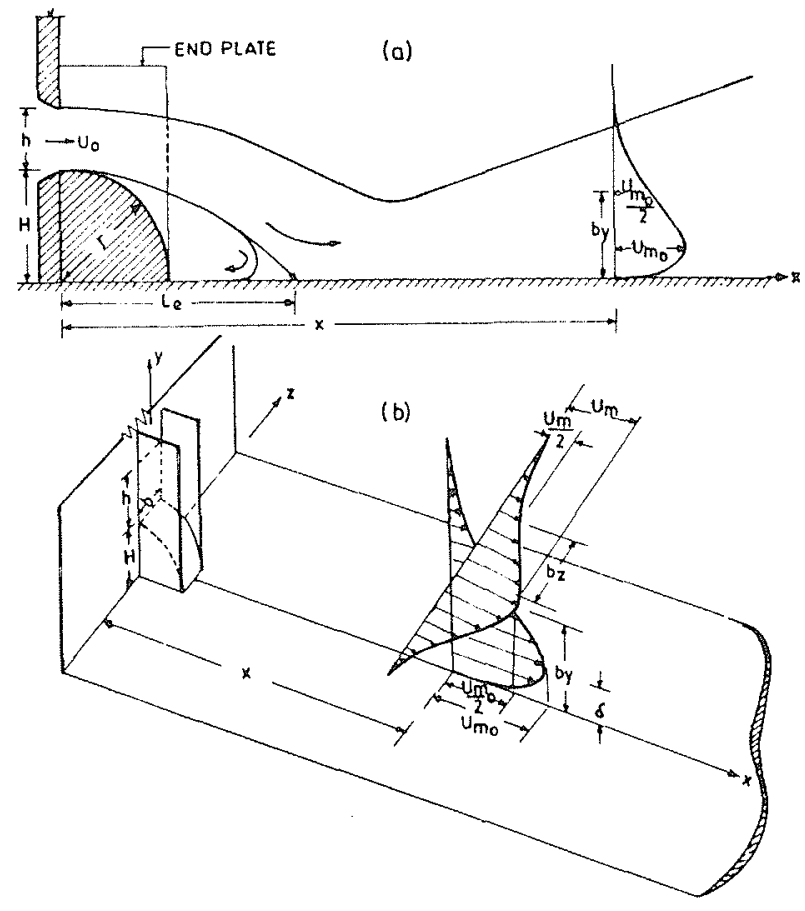

Figure 1 - Definition sketch.

conditions. For large depth of submergence of the jet, oscillatory movement from one side of the channel to another results. However, if the jet is deflected towards the bed, the impinging jet steadies the flow in the downstream channel. Naib [3] studied the gross characteristics of a circular jet directed at different angles to the wall. Another aspect of practical significance is that if the buoyant jet emanating from sewage outfall ports is made to reattach to the sea-bed, a greater degree of dilution can be achieved near the sea-surface [11]. Thus, the behaviour of the deflected jet is of importance in designing stilling basins for pipe chutes and sewage disposal devices.

Davis and Winarto [2] have studied the influence of the displacement of a circular nozzle, from the plane of the wall, on the velocity decay and growth of the jet. In order to understand the bulk properties of a somewhat related three-dimensional jet, which reattaches to the wall because of Coanda effect, an experimental investigation was undertaken and the results are presented herein.

The results can be useful in analysing the characteristics of flow deeply submerged, three-dimensional, outlets located at some distance above the bed of the downstream channel. For the outlets considered here, the flow at the efflux section is parallel to the channel bed.

Consider the case of a three-dimensional jet with a uniform velocity $U_{0}$ issuing from an opening of height $h$ (fig. 1), situated at a distance $H$ above the bed. As the tailwater depth is considered to be very large, the effect of the free surface is negligible. Two parallel end-plates, having a spacing equal to the width of the outlet, aid the flow to reattach to the bed. After leaving the threedimensional nozzle, the jet behaves as a plane jet and it curves towards the bed due to a reduction in pressure below the jet. The reattached jet encloses a region of separated flow, and downstream of the reattached line an impingement zone exists, where, the pressures are higher than the ambient pressure. Thus, a steep favourable pressure gradient exists in the impingement zone. At the end of this zone, the high velocity stream undergoes turbulent diffusion akin to that of a three-dimensional wall jet under zero pressure gradient conditions. The flow beyond the impingement zone is known as the 'reattached wall jet'. The present investigation deals with the mean characteristics of the reattached wall jet for small heights of the step. The mean and fluctuating pressure intensities on the bed are also measured.

\section{Experiments}

Experiments were conducted with air jets discharging into a quiescent ambient. To get a near uniform efflux velocity at the nozzle, flow straighteners, wire mesh screens and a standard flow transition were used in the plenum chamber, whose pressure could be adjusted to any desired value. The height of the step below the nozzle was varied from zero to $2.5 \mathrm{~cm}$ by providing a smooth flat plate $($ size $180 \mathrm{~cm} \times 114 \mathrm{~cm}$ ) at the desired distance from the invert of the outlet and by holding the plate normal to the $x-y$ plane. A pair of plexiglass end plates $2.5 \mathrm{~cm}$ long were provided (fig. 1). Simultaneously, a segment of a plexiglass cylinder of outer radius $2.5 \mathrm{~cm}$ was also provided to ensure that the three-dimensional jet reattaches easily to the bed. The size of the nozzle tested was $1 \mathrm{~cm}$ wide and $1.5 \mathrm{~cm}$ high. Throughout the investigation the efflux velocity $U_{0}$ was commonly maintained at $100 \mathrm{~m} / \mathrm{s}$ with a few runs being made at $U_{0}=71$ and $51 \mathrm{~m} / \mathrm{s}$.

The velocity field was measured by means of $1 \mathrm{~mm}$ outer diameter total head tube. No corrections were applied for the angle of attack, pitot displacement and effect of turbulence. The shear stress on the bed was measured by means of a Preston tube of external diameter $1 \mathrm{~mm}$ and the calibration curve given by Patel [4] was used in the computation. The pressure on the bed was measured by means of $1 \mathrm{~mm}$ diameter piezometer holes drilled on the bed at an average distance of $0.5 \mathrm{~cm}$ apart. A differential type of pressure transducer was used to record the pressure fluctuations on a $x-y$ plotter and the $r m s$ values of the fluc-

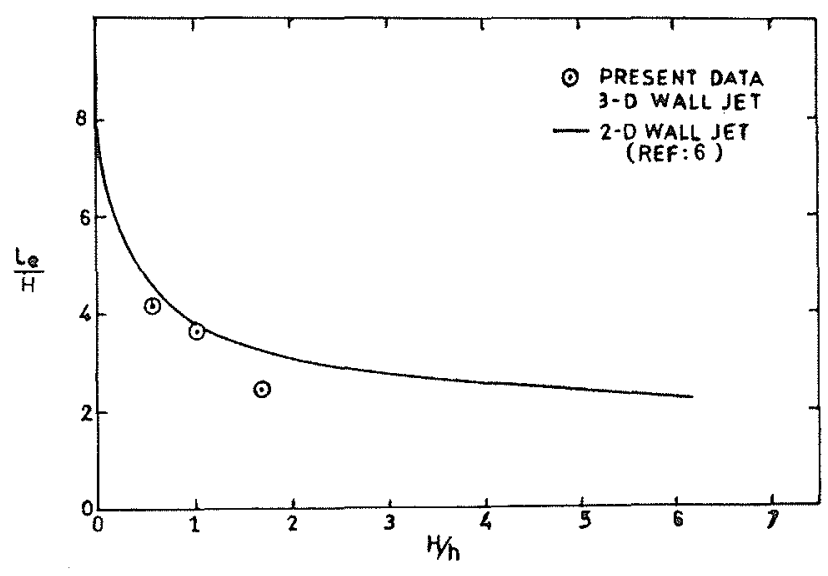

Figure 2 - Variation of eddy length with height of step. 
tuating component were found using a method due to Tucker [14]. A screw driver probe $3 \mathrm{~mm}$ in diameter, which is insensitive to angle of attack, was used to measure the pressure field in the eddy region.

\section{Analysis of results}

Since two end plates are provided at the efflux section, the flow in the initial region will behave like a plane reattaching flow. Beyond the impinging zone the flow will exhibit three dimensional characteristics. The flow can threrefore be analysed in three distinctly different zones.

\subsection{Initial or Plane Jet Region}

In this region the length of the eddy $L_{e}$, can be expressed in the following nondimensional form [6]

$$
\frac{L_{e}}{H}=f\left(\frac{U_{0} h}{\nu}, \frac{H}{h}\right)
$$

For sufficiently large Reynolds number, $R_{h}=\frac{U_{0} h}{\nu}$,

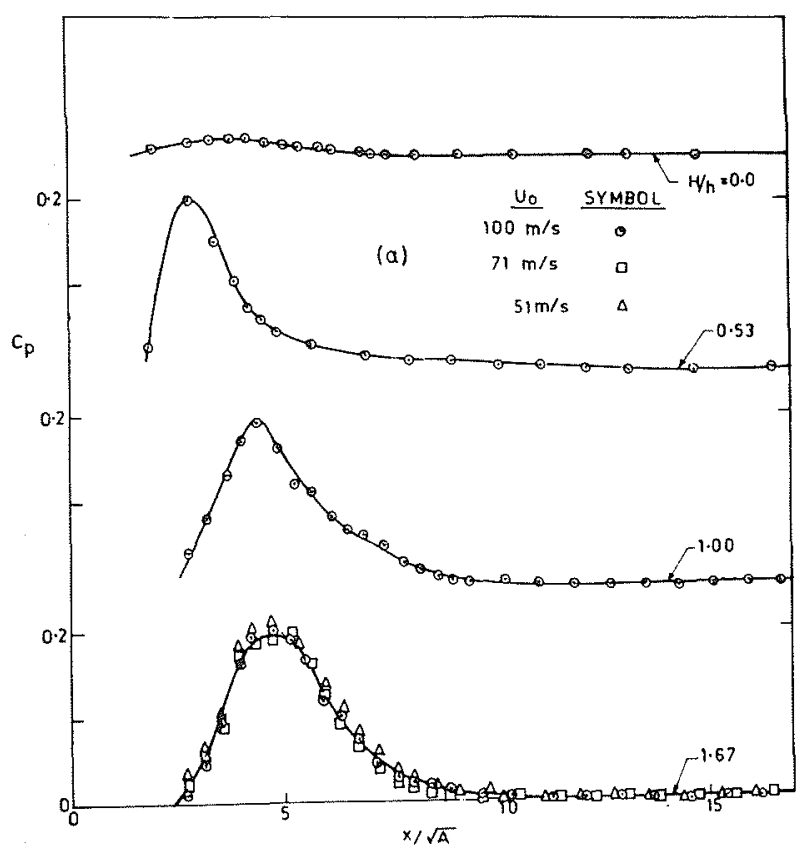

Figure $3 a-$ Mean wall pressure coefficient

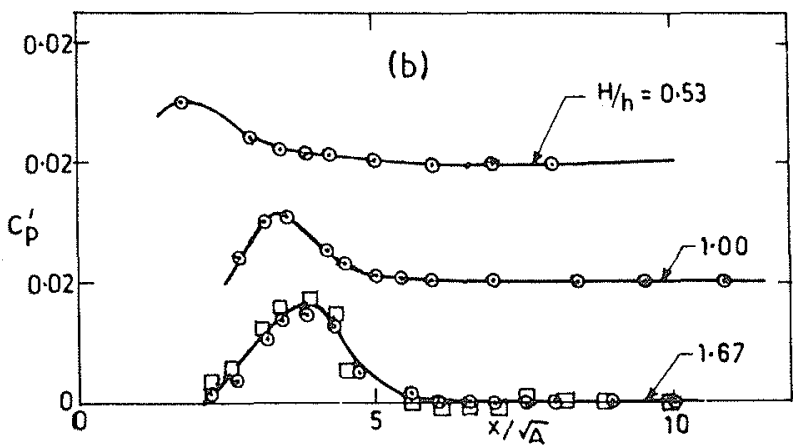

Figure $3 b-$ Fluctuating wall pressure coefficient

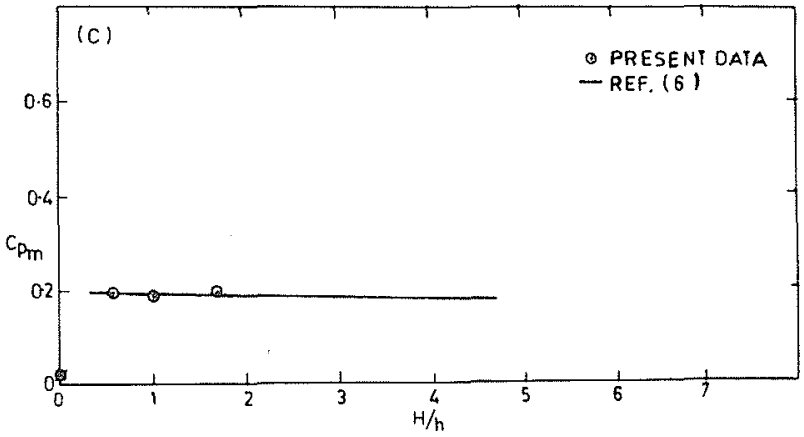

Figure $3 c-$ Variation of $C_{p m}$ with height of step.

viscosity is known to have very little effect on turbulent mixing and equation (1) can be written as

$$
\frac{L_{e}}{H}=f\left(\frac{H}{h}\right)
$$

Results from reference [6], in the range of step heights tested herein, are compared with the present data in figure 2 , and some disagreement between the two can be seen. It should be noted that the results taken from reference [6] are for flows with an abrupt drop below the plane slot. In the present case the jet grows on a cylindrical surface before reattaching to the bed. The presence of the cylindrical surface somewhat reduces the length of eddy.

\subsection{Impingement Region}

In this region the pressures on the wall are in excess of the zero ambient pressure. A typical plot of the mean pressure coefficient, $C_{p}$, taken on the wall and along the axis of the jet is shown in figure $3 \mathrm{a}$. The position at which the wall pressure is a maximum is considered to be the location of the reattachment line. If $C_{p m}$ is the maximum pressure coefficient recorded on the bed of the channel, for large Reynolds number flows, when the viscous effects are negligible, the coefficient can be expressed as a function of the step hight $(H / h)$. The $C_{p m}$ values recorded in the present investigation are plotted against $(H / h)$ in figure $3 \mathrm{c}$, and the mean line for a plane jet is taken from reference [6] for comparison. For zero step height the $C_{p m}$ value shifts towards zero, in accordance with the physical nature of the flow field.

The fluctuating pressure coefficients, $C_{p}^{\prime}$, were measured at various locations for different step heights and the results are represented in figure $3 \mathrm{~b}$. Reduction in the intensity of fluctuation with a reduction in the step height can clearly be seen. At zero step height the intensity of fluctuation is practically zero.

\subsection{Wall Jet Region}

At short distances beyond the impingement line, the excess pressure almost vanishes as a result of acceleration in the forward flow and the velocity profiles resemble that of a three-dimensional wall jet. The velocity profiles at various locations, taken in a direction normal to the bed and in the $x-y$ plane of symmetry, are plotted in the nondimensional form as $\left(u_{m} / u_{m o}\right)$ versus $\left(y / b_{y}\right)$. Here, $u_{m o}$ is the maximum velocity at the section and $b_{y}$ is 


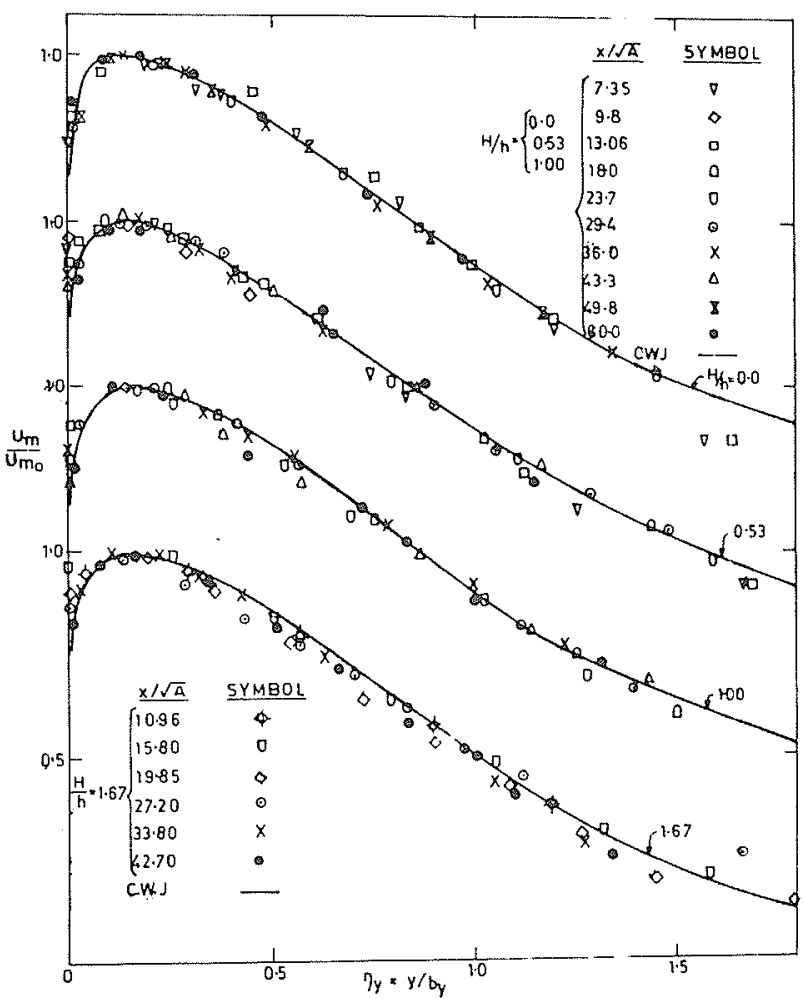

Figure 4 - Nondimensional velocity profiles normal to wall.

the distance from the bed at which $u_{m}=u_{m o} / 2$ and the velocity gradient is negative. Results for various heights of steps are presented in figure 4. In this plot, for a given step height $H / t$, the velocity profiles have collapsed into a single curve beyond a certain $x / \sqrt{A}$ value. Herein, $\sqrt{A}$ was selected to nondimensionalise the distance ' $x$ ' as it is the characteristic length in case of

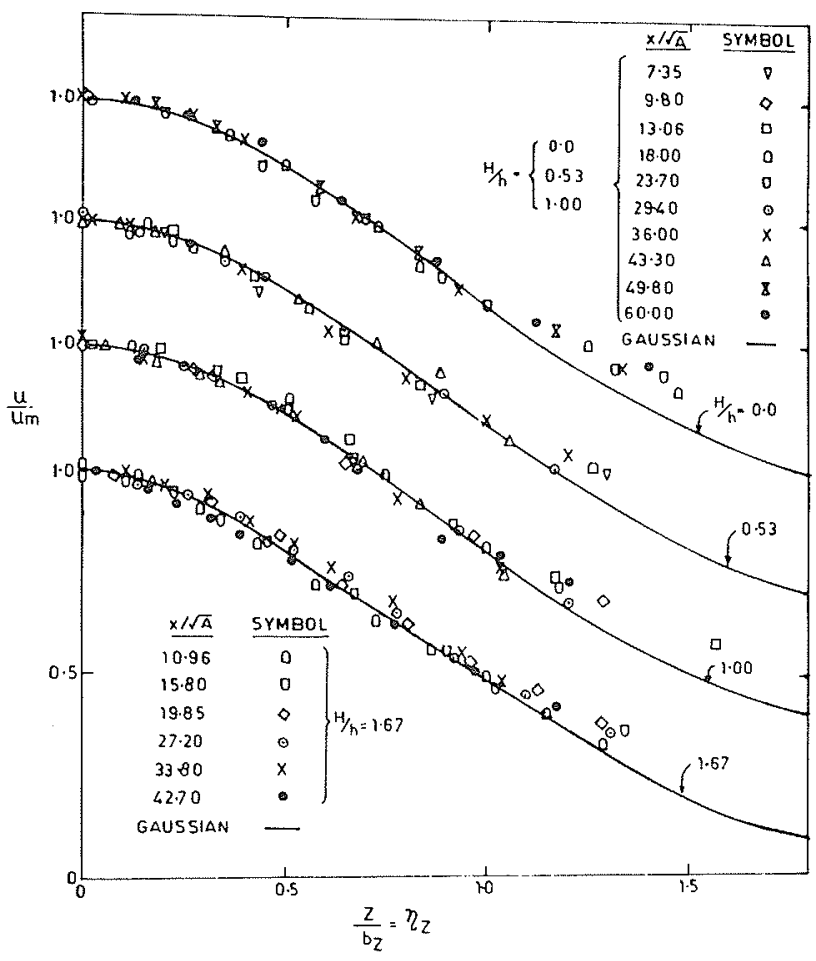

Figure 5 - Nondimensional velocity profile parallel to wall.

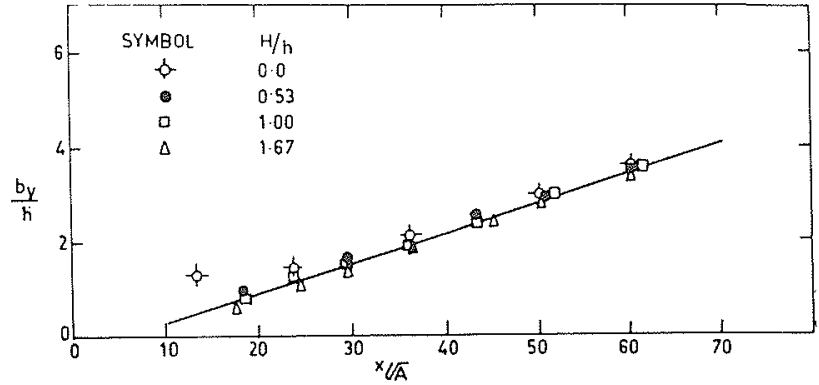

Figure 6 - Variation of length scale $b_{y}$.

three-dimensional jets [7]. The classical wall jet profile is shown in the same plot as a solid line and can be seen to describe the present observations quite closely. The minimum distance $x_{s}$ beyond which the velocity profiles are similar depends on the step height. Qualitatively, one can observe that $x_{s}$ increases with an increase in the step height, and is a minimum of about $7.4 \sqrt{A}$ for zero height of the step.

Velocity profiles were also taken in planes parallel to the bed and the distribution is shown in the nondimensional form $u / u_{m}$ versus $z / b_{z}$, where $u_{m}$ is the velocity on the $z=0$ plane and $b_{z}$ is the distance along the $Z$ direction, measured from the plane of symmetry, at which $u=u_{m} / 2$. Typical results from the present investigation are shown in figure 5 for planes lying very near the bed. Here again, one can see that all the velocity profiles collapse into a single curve which is very well described by a Gaussian distribution shown as a solid line in the figure.

\subsection{Length Scales}

The tow length scales used in the foregoing similarity analysis are respectively $b_{y}$ and $b_{z}$; The variation of these two quantities with distance ' $x$ ' for various step heights is shown in nondimensional form, in figure 6 and 7 . From figure 6 , one can observe that growth of $b_{y}$ is essentially linear for all step heights. Moreover, the height of the step tested herein does not seem to affect the $b_{y}$ scale. It may, however, be noted that because of the end plates provided in this series of experiments, the $b_{y}$-growth rate for zero step height shown in the figure is somewhat different from that of the conventional three-dimensional wall jet results reported elsewhere [7].

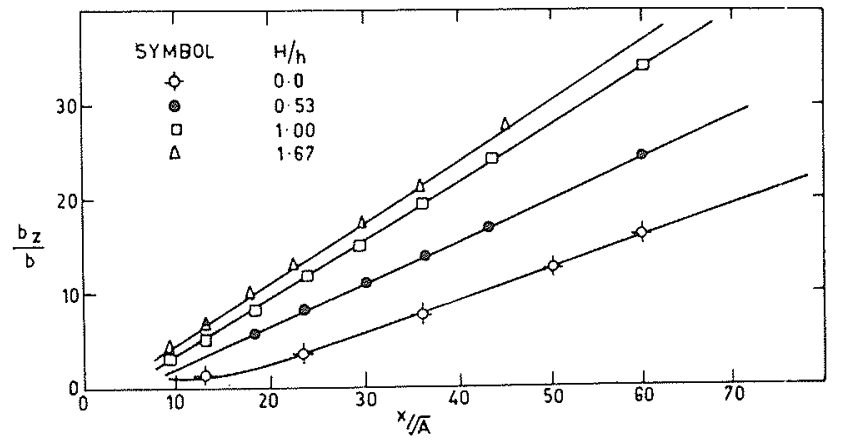

Figure 7 - Variation of length scale $b_{z}$. 


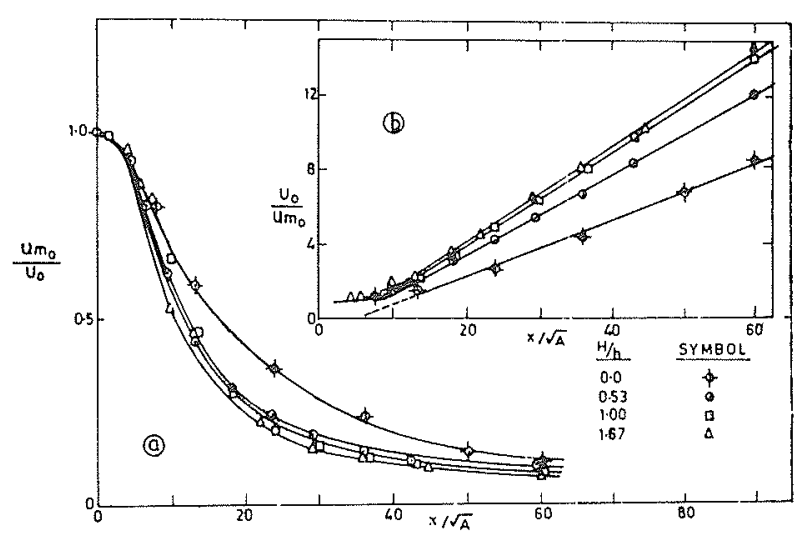

Figure $8 \mathrm{a}-\mathrm{b}-\mathrm{Ax}$ is velocity decay.

The length scale $b_{z}$ is also seen to vary linearly with distance $x$. From figure 7 we can observe that the step height plays an important role in the $b_{z}$ growth. The larger the step height, the faster does the jet grow in the transverse direction. Because of the fast rate of spread of the jet, one would expect the forward velocity of the flow to decay faster. This aspect is discussed in the following section.

\subsection{Velocity Decay}

The maximum velocity $u_{m o}$ at any particular section is a function of the streamwise distance and, in general, decreases with ' $x$ ' because of flow entrainment. The variation $u_{m o} / U_{o}$ with $x / \sqrt{A}$ is shown in figure $8 \mathrm{a}$ for various values of $H / h$. For step heights other than zero, it can be seen that the $u_{m o} / U_{o}$ decreases rapidly.

The velocity decay results are also plotted as $U_{o} / u_{m o}$ versus $x / \sqrt{A}$ and from figure $8 \mathrm{~b}$, in-set, a linear relationship is seen to exist for all step heights. The virtual origin is located at a distance of about 5 times $\sqrt{A}$ from the face of the nozzle. For application in practice, it is therefore desirable to express the velocity decay as

$$
\frac{u_{m o}}{U_{o}}=\frac{C}{[x / \sqrt{A}]}
$$

where the constant $C$ would depend on the step height $H / h$. The variation of $C$ in the present investigation is shown in figure 9.

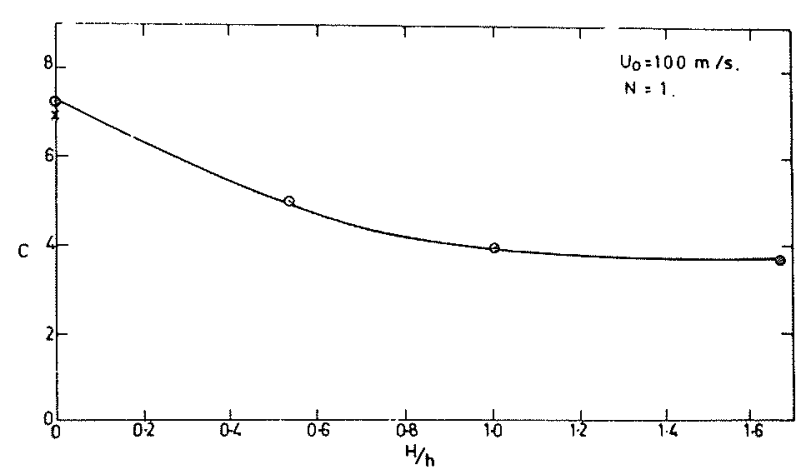

Figure 9-Coefficient $\mathrm{C}$ in Equation (3).

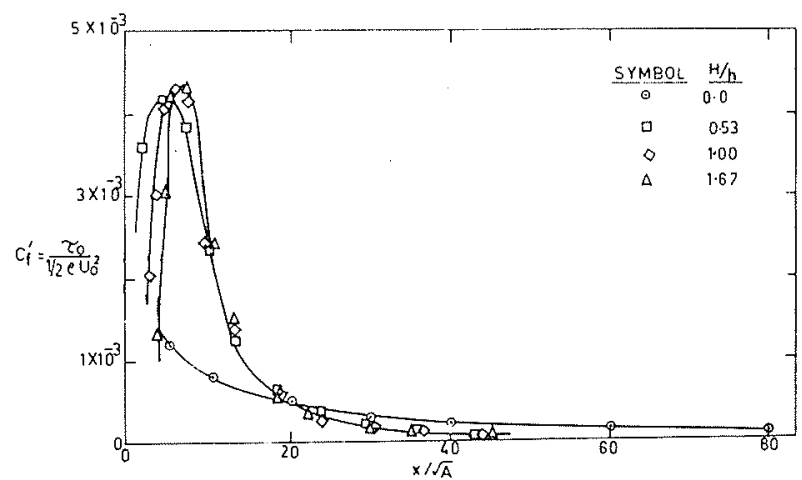

Figure 10 - Variation of coefficient of wall shear.

\subsection{Bed Shear Stress}

The bed shear stresses were measured by a Preston tube. This technique will give a reasonable estimate in the wall jet region, but is likely to yield only approximate result in the impingement region (because of the large pressure gradients and flow reversal). The variation of $\tau_{o}$ in nondimensional from is shown in figure 10 for various step heights. It can be observed that $\tau_{o}$ is zero near the reattachement line, attains a maximum at a short distance downstream, and then decreases gradually with the streamwise distance ' $x$ '. The location of the maximum value depends on the step size. The variation of the local coefficient of skin friction, $c_{f}$, is shown in figure 11 . Here, again, the variation of $c_{f}$ with distance $x / \sqrt{A}$ can be seen to be almost independent of the step heights.

\section{Conclusions}

Flow from three-dimensional outlets, situated at some elevation above the bed of the conveyance channel, with suitable end-plates and a curved solid surface underneath, will reattach to the bed. The growth of the jet beyond the impingement region was studied as a wall jet and the following observations were made :

1 . Beyond a certain distance downstream of the reattachment line, the velocity profiles in the $x-y$ plane of symmetry and the $x-z$ planes are similar.

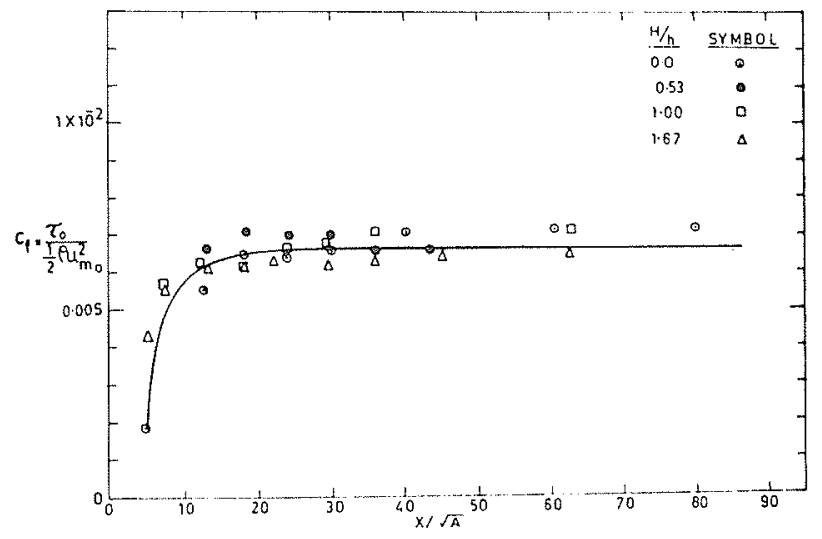

Figure 11 - Local skin friction coefficient. 
2. The length scales $b_{y}$ and $b_{z}$ vary linearly with distance $x$. Although the growth of the reattached jet normal to bed is not materially altered by the height of step provided, the growth in the transverse direction is faster when the outlet is situated above the bed.

3. With the provision of a step height the maximum velocity $u_{m o}$ decays more rapidly, when compared to the conventional three-dimensional wall jet located at the bed level. With an increase in the height of the step the decay rate also increases. For the range of step heights tested herein, $u_{\text {mo }}$ varies linearly with $1 / x$. 4. The local skin friction coefficient $c_{f}$ is a function of the distance $x / \sqrt{A}$ alone, and for all practical purposes can be considered to be independent of the height of steps investigated.

\section{References}

[1] BOURQUE C. and NEWMAN B.G. - Reattachment of a Two-Dimensional Incompressible Jet to an Adjacent Flat Plate, The Aeronautical Quarterly, Vol. XI. Aug., 1960.

[2] DAVIS M.R. and WINARTO H. - Jet Diffusion from a Circular Nozzle, Journal of Fluid Mechanics, Vol. 101, Part 1, Nov., 1980.

[3] NAIB S.K.A. - Deflexion of a Submerged Round Jet to Increase Lateral Spreading, La Houille Blanche, No. 6, 1974.

[4] PATEL V.C. - Calibration of the Preston Tube and Limitations on its Use in Pressure Gradients, Journal of Fluid Mechanics, Vol. 23, Part 1, March, 1965.
[5] RAJARATNAM N. and SUBRAMANYA K. - The Diffusion of Rectangular Wall Jets in Wide Channels, Journal of Hydraulic Research, IAHR, Vol. 5, March, 1967.

[6] RAJARATNAM N. and SUBR AMANYA K. - Plane Turbulent Reattached Wall Jets, Journal of the Hydraulics Division, Proc. ASCE, Vol. 94, No. Hy. 1, Jan. 1968.

[7] RAJARATNAM N. and PANI B.S. - Three-Dimensional Turbulent Wall Jets, Journal of the Hydraulics Division, Proc. ASCE, Vol. 100, No. Hy. 1, Jan, 1974.

[8] SFORZA P.M., STEIGER M.H. and TRENTACOSTE N. Studies on Three-Dimensional Viscous Jets, AIAA Journal, Vol. 4, No. 5, May, 1966.

[9] SFORZA P.M., and HERBST G. - A Study of ThreeDimensional Incompressible Turbulent Wall Jets, AIAA Joumal, Vol. 8, No. 2, Feb., 1970.

[10] SCHWARZ W.H. and COSART H.P. - The Two-Dimensional Turbulent Wall Jets, Journal of Fluid Mechanics, Vol. 10, June, 1961.

[11] SHARP J.J. - The Use of a Buoyant Wall Jet to Improve the Dilution of a Submerged Outfall, Proc. Inst. of Civil Engineers, London, Part 2, Sept. 1975.

[12] SRINIVASAMURTHY M.C. - Experimental Investigation of Flow Downstream of a Sluice Gate, Ph.D. Thesis, Civil Engineering Department, Indian Institute of Technology, Bombay, India, 1974.

[13] TRENTA COSTE N., PASQUAL P. and SFORZA P.M. Further Experimental Results for Three-Dimensional Free Jets, AIAA Journal, Vol. 5, No. 5, May, 1967.

[14] TUCKER M.J. - Simple Measurement of Wave Records, Proc. Conf. Wave Recording Civ. Engrs. National Institute of Oceanography, Jan. 1961. (Taken from Appendix of 'Derivation of a Design Wave from Instrumental Records of Sea Waves', by Draper, L. Institute of Civil Engineers, London, Procds. 26, 1963). 